\title{
Determination of Trace Elements in Carbon Steel by Inductively Coupled Plasma Atomic Emission Spectrometry
}

\author{
A. Sengupta, B. Rajeswari, R.M. Kadam* ${ }^{\star}$ and R. Acharya \\ Radiochemistry Division, Bhabha Atomic Research Centre, \\ Trombay, Mumbai - 400 085, India
}

\section{INTRODUCTION}

Carbon steel, also known as plain carbon steel, is a metal alloy consisting of the elements iron $(\mathrm{Fe})$ and carbon (C). According to the American Iron and Steel Institute (AISI), "...steel is considered to be carbon steel when no minimum content is specified or required for chromium, cobalt, columbium, molybdenum, nickel, titanium, tungsten, vanadium, zirconium or any other element to be added to obtain a desired alloying effect. The carbon steel can be classified into four types as mild, medium, high and very high depending on the carbon content which varies from $0.05 \%$ to $2.1 \%$ (1)."

In the nuclear industry, carbon steel finds use in feeder pipes for the reactors and as containers for storage of Intermediate level Liquid Waste (ILW). Carbon steel is also used for medical devices, razor blades, cutlery, and different types of springs. Since trace impurity elements can have a significant effect on the quality of steel, strict quality control measures are required.

The present study deals mainly with the direct determination of some trace elements in carbon steel using inductively coupled plasma atomic emission spectrometry (ICPAES). It is significant to mention that iron, which forms one of the main constituents of carbon steel and has a multi-electronic configuration with line-rich emission spectra, tends to interfere in the determination of trace impurities. If no chemical/physical separation

*Corresponding autbor.

E-mail: rmkadam2003@yaboo.co.in

\section{ABSTRACT}

Studies have been carried out for the direct determination of some common metallic elements ( $\mathrm{Pb}, \mathrm{Cd}, \mathrm{Mn}, \mathrm{Mo}, \mathrm{Mg}, \mathrm{Si}, \mathrm{V}, \mathrm{Cu}$, $\mathrm{Ag}, \mathrm{Ca}, \mathrm{Na}, \mathrm{Li}, \mathrm{Cr}, \mathrm{Zn}, \mathrm{Ni}, \mathrm{Co}, \mathrm{B}$, and $\mathrm{Al}$ ) in a carbon steel matrix using inductively coupled plasma atomic emission spectrometry (ICP-AES). In addition, a systematic study was carried out to monitor the contribution from iron (Fe), which forms one of the main constituents of carbon steel, on the various analytical wavelengths of these elements. Interference-free wavelengths were identified for a few of the elements while, for others, appropriate correction factors were determined and applied to obtain the final estimates.

This method was found to be useful for the determination of the elements of interest and applied to the analysis of two carbon steel samples. A comparative study was carried out using instrumental neutron activation analysis (INAA) to validate the ICP-AES data obtained after spectral interference correction for Fe. Though both ICP-AES and INAA are simultaneous multielemental analytical techniques with improved precision and detection limits, ICP-AES is preferred over INAA because it is simple, less time-consuming, and less costly. In addition, boron is difficult to determine using INAA due to its very short half life of the formed isotope, while $\mathrm{Pb}$ and Si cannot be determined due to the very low neutron absorption cross section. is performed prior to ICP-AES analysis, the spectral interference from iron on the analyte under study needs to be investigated. Therefore, a systematic study was carried out to monitor the contribution of iron on the analytical lines of $\mathrm{Pb}, \mathrm{Cd}$, $\mathrm{Mn}, \mathrm{Mo}, \mathrm{Mg}, \mathrm{Si}, \mathrm{V}, \mathrm{Cu}, \mathrm{Ag}, \mathrm{Ca}, \mathrm{Na}$, $\mathrm{Li}, \mathrm{Cr}, \mathrm{Zn}, \mathrm{Ni}, \mathrm{Co}, \mathrm{B}$, and $\mathrm{Al}$. For some of the elements, interferencefree analytical wavelengths were identified while for other elements, appropriate correction factors were calculated and applied to obtain the final estimates. The method developed has been used for the analysis of two carbon steel samples (obtained from Rajasthan Atomic Power Station (RAPS) - 2, India). Several methods for trace elemental determination in high purity iron have been reported in the literature. Some of these include neutron activation analysis $(2,3)$, atomic absorption spectrometry (4-7), and atomic emission spectrometry $(8$, 9). ICP-AES is widely recognized as a suitable technique for the determination of trace elements in nuclear materials (10-15) because it offers multi-element capability, has a large dynamic range, and effective background correction. However, several problems have been reported, such as spectral interferences owing to matrix components, nebulizer blockage due to a high solid content in the solution, or analyte emission enhancements $(16,17)$. Studies on the effect of iron-rich matrices on the direct determination of trace impurities at the microgram levels have been reported. Chen et al. (7) measured the detection limits obtained for the determination of trace elements in dissolved iron and observed a decrease in sensitivity and a high 
spectral background. Ochsenkuhn et al. (18) investigated a preconcentration/separation method for the on-line determination by ICP-AES of gold in iron-rich matrices. Some of these reports use separation procedures such as ion-exchange, co-precipitation, and a variety of solvent extraction techniques (9, 18 - 20). Interference studies related to the iron concentration in the sample and the selection of spectral lines have also been published (21 - 24).

Spectral interferences in ICP-AES can be seriously detrimental to the accuracy and reliability of trace element determination, particularly when analysis is performed in the presence of high concentrations of matrix constituents. Moreover, the most sensitive lines for many of the elements are already in use; thus, any change in the analytical lines to avoid interferences may result in reduced sensitivity. This necessitates an accurate correction to overcome any spectral interference during the course of the analysis.

Neutron activation analysis is a sensitive, multi-elemental, nondestructive, and powerful isotopespecific nuclear analytical technique and was used in this study to compare the analytical data obtained by ICP-AES. This technique is based on irradiation of a sample with neutrons and subsequent measurement of the induced radioactivity for determination of the concentration of an element. When a neutron interacts with the target nucleus via a non-elastic collision, a compound nucleus is formed in an excited state. The excitation energy of the compound nucleus is due to the binding energy of the neutron with the nucleus. The compound nucleus will almost instantaneously deexcite into a more stable configuration through emission of one or more characteristic prompt gamma rays. In many cases, this new configuration yields a radioactive nucleus, which decays to a daughter nucleus through $\beta$ decay, according to the unique half-life of the radioactive nucleus, followed by de-excitation of a daughter nucleus by emission of one or more characteristic delayed gamma rays.

The radioactivity formed at the end of the irradiation is given by:

Activity ,

$A=N \sigma \phi\left(1-e^{-\lambda \text { tirr }}\right) \mathrm{e}^{-\lambda \mathrm{td}}$

$A=\left(N_{\mathrm{A}}\right.$ w $\left.\theta / \mathrm{M}\right) \sigma \phi\left(1-\mathrm{e}^{-\lambda \text { tirr }}\right) \mathrm{e}^{-\lambda \mathrm{td}}$

where $A$ is induced activity in dps (disintegration per second), $\mathrm{N}$ is number of target atoms, $\sigma$ is the neutron cross section, $\phi$ is the neutron flux at the irradiation position, $\lambda$ is the decay constant $(=0.693$ / $\mathrm{T} 1 / 2), \mathrm{N}_{\mathrm{A}}$ is Avogadro number, $\mathrm{w}$ is mass of the element, $\theta$ is isotopic abundance of target isotope, $M$ is average atomic mass of the element, tirr is irradiation time, and td is cooling time (time between end of irradiation and start of counting), (1-e $\left.\mathrm{e}^{-\lambda \text { tirr }}\right)$ is the saturation factor (S) and $\mathrm{e}^{-\lambda t \mathrm{td}}$ is the decay factor (D).
But in the laboratory, radioactivity is measured in terms of counts per second (cps), which is given by:

$$
A(\mathrm{cps})=\mathrm{A}(\mathrm{dps}) . \varepsilon \cdot \gamma_{\mathrm{ab}}
$$

where $\varepsilon$ is efficiency of detector for the measured gamma radiation in a particular geometry and $\gamma_{a b}$ is the gamma abundance.

\section{EXPERIMENTAL}

\section{Instrumentation}

A Jobin-Yvon Panorama axial ICP spectrometer was used, equipped with a polychromator with 35 fixed analytical wavelengths and a limited sequential facility to select any analytical line within $2.2 \mathrm{~nm}$ of the polychromator lines. For nebulization, a pneumatic crossflow nebulizer and a peristaltic pump were employed with a sample flow rate of $1 \mathrm{~mL} / \mathrm{min}$. The resolution of the spectrometer was $0.028 \mathrm{~nm}$. The main operating conditions of the spectrometer are listed in Table I.

TABLE I

Specifications and ICP-AES Operating Conditions

\begin{tabular}{lr}
\hline Spectrometer & Jobin-Yvon Panorama Axial ICP \\
\hline Optical Design & $1-\mathrm{m}$ Czerny Turner \\
Grating & Two holographic, ion-etched optical gratings \\
Groove Density & 2400 grooves $/ \mathrm{mm}, 4320$ grooves $/ \mathrm{mm}$ \\
Grating Size & $110 \times 110 \mathrm{~mm}$ \\
Wavelength range & $120-800 \mathrm{~nm}$ \\
Bandpass & $0.0023 \mathrm{~nm}$ from $120-340 \mathrm{~nm}$ \\
& $0.0046 \mathrm{~nm}$ from $340-800 \mathrm{~nm}$ \\
Thermal Stabilization & Controlled to $30 \pm 1{ }^{\circ} \mathrm{C}$ \\
\hline RF Generator & $40.68 \mathrm{MHz}$ \\
\hline Frequency & Dual channel $(12 \mathrm{roller})$ \\
Pump & Pneumatic concentric \\
Nebulizer & $13 \mathrm{~L} / \mathrm{min}$ \\
Operating Condition & $10 \mathrm{~s}$ \\
Ar Plasma Flow & $<10 \mathrm{~W}$ \\
Integration Time & $1 \mathrm{~mL} / \mathrm{min}$ \\
Reflected Power & \\
Sample Rate & \\
\hline
\end{tabular}




\section{Preparation of Standards and Samples}

Suprapur ${ }^{\circledR}$ acids (E. Merck, Darmstadt, Germany) and quartz double-distilled water were used for the preparation of the standards and the sample solutions. Multi-element standard solutions were prepared from commercially available Fe SpecPure ${ }^{\circledR}$ solutions (Johnson Matthey Chemicals, Limited, London, UK) by appropriate dilution with $0.5 \mathrm{M} \mathrm{HCl}$. These solutions were used to obtain calibration plots during ICP-AES analysis. A multi-point standardization was carried out using $0.5 \mathrm{M} \mathrm{HCl}$ as the lower standards and $0.5-100 \mu \mathrm{g} / \mathrm{mL}$ of the corresponding elemental standard as the higher standards, respectively. The Fe interference studies were carried out using SpecPure Fe solutions in the concentration range of $100-1000 \mu \mathrm{g} / \mathrm{mL}$ to monitor the contribution of Fe at the various analyte wavelengths. Similarly, 0.5 M HCl served as a reagent blank to monitor any contribution from the blank. Two carbon steel samples of $25 \mathrm{mg}$ each, collected from feeder pipes (Rajasthan Atomic Power Station-2, India), were dissolved in Suprapur $\mathrm{HCl}$ (E. Merck), and made up to $25-\mathrm{mL}$ volume with $1 \mathrm{M} \mathrm{HCl}$ to obtain a $1-\mathrm{mg} / \mathrm{mL}$ sample solution. These samples were analyzed for the 18 trace elements using the present method.

\section{Procedure}

For carrying out the analysis of the carbon steel samples, standardization was performed with a multipoint calibration. The analytical data obtained for these samples are listed in Table II. Our studies were further extended to monitor the Fe matrix interference on the analyte elements. Solutions containing 100 $\mu \mathrm{g} / \mathrm{mL}, 500 \mu \mathrm{g} / \mathrm{mL}$, and $1000 \mu \mathrm{g} / \mathrm{mL}$ amounts of Fe were aspirated into the ICP and the analyte concentrations monitored at their respective wavelengths. The results are listed in Table III which show that the contribution of iron for the specified analytical channel is below the detection limits (BDL) of the specified elements.

\section{Neutron Activation Analysis}

Instrumental neutron activation analysis (NAA without any chemical separation) was carried out by irradiation of the sample using the DHRUVA research reactor (at the Bhabha Atomic Research Centre, BARC, India) using a neutron flux of 1013 for 1 minute against commercially available multi-standards. The irradiated samples and standards were mounted on PVC plates and counted for activity content using an HPGe detector connected to a multi-channel analyzer. The concentration of the elements were determined by monitoring their characteristic gamma rays.

\section{TABLE II}

Determination of Trace Elements in Carbon Steel Samples

\begin{tabular}{lccc}
\hline Element & $\begin{array}{c}\text { Wavelength } \\
(\mathrm{nm})\end{array}$ & $\begin{array}{c}\text { Amount estimated in } \\
\text { Carbon Steel-1* } \\
(\mu \mathrm{g} / \mathrm{mg})\end{array}$ & $\begin{array}{c}\text { Carbon Steel-2* } \\
(\mu \mathrm{mg})\end{array}$ \\
\hline $\mathrm{Cr}$ & 205.559 & 3.41 & 0.16 \\
$\mathrm{Zn}$ & 213.856 & 0.15 & 0.12 \\
$\mathrm{~Pb}$ & 220.353 & 0.29 & 0.25 \\
$\mathrm{Cd}$ & 228.802 & $\mathrm{BDL}$ & $\mathrm{BDL}$ \\
$\mathrm{Ni}$ & 232.003 & 3.70 & 0.54 \\
$\mathrm{Co}$ & 237.862 & 1.25 & 1.31 \\
$\mathrm{~B}$ & 249.678 & 5.26 & 6.10 \\
$\mathrm{Mn}$ & 257.610 & 7.42 & 6.21 \\
$\mathrm{Mo}$ & 281.615 & 4.59 & 0.67 \\
$\mathrm{Mg}$ & 285.213 & $\mathrm{BDL}$ & $\mathrm{BDL}$ \\
$\mathrm{Si}$ & 288.158 & 6.58 & 6.50 \\
$\mathrm{Al}$ & 308.215 & 0.51 & 0.49 \\
$\mathrm{~V}$ & 310.230 & 0.14 & 0.12 \\
$\mathrm{Cu}$ & 324.754 & 1.62 & 0.33 \\
$\mathrm{Ca}$ & 396.847 & $\mathrm{BDL}$ & $\mathrm{BDL}$ \\
$\mathrm{Na}$ & 589.592 & 0.40 & 0.23 \\
\hline $\mathrm{BL}$ & & &
\end{tabular}

$\mathrm{BDL}=$ Below detection limits.

*All values are corrected for the contribution due to iron.
TABLE III

Fe Interference-Free Spectral Lines Selected for Spectral Scans Elements Wavelength $100 \mu \mathrm{g} / \mathrm{mL} \quad 500 \mu \mathrm{g} / \mathrm{mL} \quad 1000 \mu \mathrm{g} / \mathrm{mL}$

\begin{tabular}{lllll} 
& $(\mathrm{nm})$ & of Fe & of Fe & of Fe \\
\hline $\mathrm{Pb}$ & 220.353 & $\mathrm{BDL}$ & $\mathrm{BDL}$ & $\mathrm{BDL}$ \\
$\mathrm{Cd}$ & 228.802 & $\mathrm{BDL}$ & $\mathrm{BDL}$ & $\mathrm{BDL}$ \\
$\mathrm{Mn}$ & 257.610 & $\mathrm{BDL}$ & $\mathrm{BDL}$ & $\mathrm{BDL}$ \\
$\mathrm{Mo}$ & 281.615 & $\mathrm{BDL}$ & $\mathrm{BDL}$ & $\mathrm{BDL}$ \\
$\mathrm{Mg}$ & 285.213 & $\mathrm{BDL}$ & $\mathrm{BDL}$ & $\mathrm{BDL}$ \\
$\mathrm{Si}$ & 288.158 & $\mathrm{BDL}$ & $\mathrm{BDL}$ & $\mathrm{BDL}$ \\
$\mathrm{V}$ & 310.230 & $\mathrm{BDL}$ & $\mathrm{BDL}$ & $\mathrm{BDL}$ \\
$\mathrm{Cu}$ & 324.754 & $\mathrm{BDL}$ & $\mathrm{BDL}$ & $\mathrm{BDL}$ \\
$\mathrm{Ag}$ & 328.068 & $\mathrm{BDL}$ & $\mathrm{BDL}$ & $\mathrm{BDL}$ \\
$\mathrm{Ca}$ & 396.847 & $\mathrm{BDL}$ & $\mathrm{BDL}$ & $\mathrm{BDL}$ \\
$\mathrm{Na}$ & 589.592 & $\mathrm{BDL}$ & $\mathrm{BDL}$ & $\mathrm{BDL}$ \\
$\mathrm{Li}$ & 670.776 & $\mathrm{BDL}$ & $\mathrm{BDL}$ & $\mathrm{BDL}$ \\
\hline
\end{tabular}

$\mathrm{BDL}=$ Below detection limit. 


\section{RESULTS AND DISCUSSION}

When a new matrix is investigated, it is essential to carry out wavelength scans in the vicinity of the analyte lines to check the presence or absence of interfering lines. Though ICP-AES is a sensitive multielemental technique, it suffers from spectral interferences. One of the ways to eliminate spectral interferences is to separate the matrix or analytes having line-rich emission spectra. Generally, solvent extraction and extraction chromatographic techniques are adopted to separate the matrix to avoid the spectral interferences and to obtain the required detection limits. However, chemical separation is time-consuming and involves handling different chemicals, which might be the source of chance contamination.

In the present study, a method was developed for the determination of trace constituents in carbon steel using ICP-AES without chemical separation of iron, which is a major constituent and rich in emission spectra. The most sensitive lines of the elements accessible with the instrument were selected, and the analyte concentrations measured while aspirating SpecPure Fe range of $100-1000 \mathrm{ug} / \mathrm{mL}$. If the contribution from the Fe solution on the analytical wavelength of a particular element is found to be less than the limits of detection of that element, then that particular solutions in the concentration interference-free from iron at that specified concentration. However, if the contribution due to iron on the analytical wavelengths of different analytes varies linearly, then the correction factors were evaluated using the following formula:

$$
\mathrm{C}=\mathrm{A}-(\text { C.F. } \mathrm{x} \text { I) }
$$

where $\mathrm{C}=$ actual concentration of the analytes in the sample, $\mathrm{A}=$ apparent concentration of the analytes determined, C.F. $=$ correction factor for the analyte at the specified wavelength due to unit concentration of iron, and $\mathrm{I}=$ concentration of iron in the sample.

Table III lists the wavelengths used for the 12 analytes $(\mathrm{Pb}, \mathrm{Cd}$, $\mathrm{Mn}, \mathrm{Mo}, \mathrm{Mg}, \mathrm{Si}, \mathrm{V}, \mathrm{Cu}, \mathrm{Ag}, \mathrm{Ca}, \mathrm{Na}$, and $\mathrm{Li}$ ) that were found to be free from Fe spectral interferences even at the $1000-\mu \mathrm{g} / \mathrm{mL}$ Fe concentration. Hence, these wavelengths can be used for trace level determinations in iron-rich materials.

Table IV lists the analyte lines that showed a significant contribution to the analyte concentration due to the presence of Fe. In case of $\mathrm{Cr}, \mathrm{Zn}, \mathrm{Ni}$, and $\mathrm{Al}$, no significant contribution of iron was observed up to $100 \mu \mathrm{g} / \mathrm{mL}$ of Fe. However, at Fe concentrations above $500 \mu \mathrm{g} / \mathrm{mL}$, contributions were observed. In case of Co and B, even at $100 \mu \mathrm{g} / \mathrm{mL}$ of $\mathrm{Fe}$, the interference was found to be more prominent. wavelength is considered to be

\section{Atomic Apectroscopy 1 Vol. 32(5), Sept./Oct. 2011}

In order to establish the magnitude of these spectral interferences, the gross peak intensities of the prepared iron solutions $(100,500$, and $1000 \mu \mathrm{g} / \mathrm{mL}$ ) and the intensities due to a reagent blank $(0.1 \mathrm{M}$ $\mathrm{HCl})$ were measured at the analyte wavelengths. From the results of the above study, appropriate correction factors for $\mathrm{Cr}, \mathrm{Zn}, \mathrm{Ni}, \mathrm{Co}$, and $\mathrm{B}$ were calculated prior to their determination, and the results obtained are listed in Table V. The results showed that the presence of an iron matrix has a significant effect on the specified analytical lines. The concentration of iron (with all other elements specified in Table V) was determined simultaneously by ICP-AES to apply the correction factor. The detection limits (sample soluiton in $\mu \mathrm{g} / \mathrm{g}$ ) of all of the elements were calculated from the calibration curve of each analyte at their specified wavelength (Table VI).

\section{Comparison of Analytical Results with NAA}

A comparative study using instrumental neutron activation analysis (INAA) was carried out to validate the results obtained by ICPAES. INAA was used because it is simple and no chemical treatment is required. As a result, the possibility for chemical contamination is negligible. In our case, INAA was employed to determine the trace constituents in carbon steel by a relative method, i.e., analysis is

TABLE V

TABLE IV

Spectral Interference of Iron on Other Analytes

\begin{tabular}{ccccc}
\hline Elements & $\begin{array}{c}\text { Wavelength } \\
\text { (nm) }\end{array}$ & $\begin{array}{c}100 \mu \mathrm{g} / \mathrm{mL} \\
\text { of Fe }\end{array}$ & $\begin{array}{c}500 \mu \mathrm{g} / \mathrm{mL} \\
\text { of Fe }\end{array}$ & $\begin{array}{c}1000 \mu \mathrm{g} / \mathrm{mL} \\
\text { of Fe }\end{array}$ \\
\hline $\mathrm{Cr}$ & 205.559 & BDL & 0.1 & 0.2 \\
$\mathrm{Zn}$ & 213.856 & BDL & 0.09 & 0.13 \\
$\mathrm{Ni}$ & 232.003 & BDL & 0.11 & 0.27 \\
$\mathrm{Co}$ & 237.862 & 0.1 & 0.52 & 0.94 \\
$\mathrm{~B}$ & 249.678 & 0.7 & 3.04 & 5.14 \\
$\mathrm{Al}$ & 308.215 & BDL & 0.27 & 0.55 \\
\hline
\end{tabular}

$\mathrm{BDL}=$ Below detection limit
Determination of Correction Factor of Analytes in Presence of Iron

\begin{tabular}{ccc}
\hline Elements & $\begin{array}{c}\text { Wavelength } \\
(\mathrm{nm})\end{array}$ & $\begin{array}{c}\text { Correction Factor } \\
(\mu \mathrm{g} / \mu \mathrm{g} \mathrm{Fe})\end{array}$ \\
\hline $\mathrm{Cr}$ & 205.559 & $2 \times 10^{-4}$ \\
$\mathrm{Zn}$ & 213.856 & $1.3 \times 10^{-4}$ \\
$\mathrm{Ni}$ & 232.003 & $2.7 \times 10^{-4}$ \\
$\mathrm{Co}$ & 237.862 & $9.4 \times 10^{-4}$ \\
$\mathrm{~B}$ & 249.678 & $5.1 \times 10^{-3}$ \\
$\mathrm{Al}$ & 308.215 & $5.5 \times 10^{-4}$ \\
\hline
\end{tabular}


done against elemental standards to minimize error in analytical results due to other experimental parameters like neutron flux and neutron absorption cross-section of the target isotope. In this method, a multi-elemental standard was coirradiated along with the sample, and the activities from the sample and the standards were measured in identical geometry with respect to the detector. This is a simple method to obtain the concentration values. Using the mass of the element in the standard $\left(\mathrm{M}_{\mathrm{x}, \mathrm{std}}\right)$, and the count rates of the standard $\left(\mathrm{CPS}_{\mathrm{x}, \mathrm{std}}\right)$ and the sample $\left(\mathrm{CPS}_{\mathrm{x}, \text { sample }}\right)$, the mass of the element is determined by the following equation:

$$
\mathrm{M}_{\mathrm{x}, \text { sample }}=\mathrm{M}_{\mathrm{x}, \mathrm{std}} \mathrm{X}\left(\mathrm{CPS}_{\mathrm{x}, \text { sample }} / \mathrm{CPS}_{\mathrm{x}, \mathrm{std}}\right)\left(\mathrm{D}_{\text {std }} / \mathrm{D}_{\text {sample }}\right)
$$

TABLE VI

Determination of Detection Limits of Analytes at Specified Wavelength

\begin{tabular}{|c|c|c|c|}
\hline Element & $\begin{array}{l}\text { Wavelength } \\
\text { (nm) }\end{array}$ & 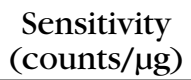 & $\begin{array}{l}\text { Detection Limit } \\
\quad(\mu \mathrm{g} / \mathrm{mg})\end{array}$ \\
\hline $\mathrm{Cr}$ & 205.559 & 15.6 & 0.02 \\
\hline $\mathrm{Zn}$ & 213.856 & 76.0 & 0.02 \\
\hline $\mathrm{Pb}$ & 220.353 & 3.0 & 0.05 \\
\hline $\mathrm{Cd}$ & 228.802 & 47.3 & 0.03 \\
\hline $\mathrm{Ni}$ & 232.003 & 6.3 & 0.02 \\
\hline Co & 237.862 & 38.3 & 0.02 \\
\hline B & 249.678 & 74.1 & 0.03 \\
\hline Mn & 257.610 & 267.7 & 0.01 \\
\hline Mo & 281.615 & 6.5 & 0.04 \\
\hline $\mathrm{Mg}$ & 285.213 & 97.1 & 0.03 \\
\hline $\mathrm{Si}$ & 288.158 & 2.7 & 0.05 \\
\hline $\mathrm{Al}$ & 308.215 & 24.3 & 0.04 \\
\hline V & 310.230 & 42.2 & 0.04 \\
\hline $\mathrm{Cu}$ & 324.754 & 133.7 & 0.01 \\
\hline $\mathrm{Ca}$ & 396.847 & 114.3 & 0.03 \\
\hline $\mathrm{Na}$ & 589.592 & 29.9 & 0.06 \\
\hline $\mathrm{Li}$ & 670.776 & 27.0 & 0.03 \\
\hline
\end{tabular}

Values in the table are on sample and solution basis. All values will be the same; only the unit will be in $\mu \mathrm{g} / \mathrm{mL}$ since the sample concentration in the solution is $1 \mathrm{mg} / \mathrm{mL}(25 \mathrm{mg}$ in $25 \mathrm{~mL})$. where $\mathbf{M}_{\mathbf{x}, \text { sample }}$ is the mass of the element in the sample, $\mathrm{D}_{\text {std }}$ and $\mathrm{D}_{\text {sample }}$ denote the decay factor of the standards and the sample, obtained by both the ICP-AES and INAA techniques (Table VII) were good agreement, indicating the ce of $\mathrm{Cr}, \mathrm{Zn}, \mathrm{Co}, \mathrm{Cu}, \mathrm{Ni}, \mathrm{Mn}$ $\mathrm{Ca}, \mathrm{Mg}$, and $\mathrm{Cd}$ were found to be the detection limits (BDL). ments (in micrograms lated using the sample background er characteristic peaks and the following formula:

$$
\begin{aligned}
& \text { D.L. }(\mu \mathrm{g})=3 \sigma_{\mathrm{b}} / \mathrm{S} \\
& \sigma_{\mathrm{b}}=\sqrt{ } \mathrm{C}_{\mathrm{b}} / \mathrm{LT} \\
& \mathrm{S}=\mathrm{CPS} / \mathrm{m}_{\mathrm{x}, \mathrm{std}}
\end{aligned}
$$

where $C_{b}$ represents the background counts, $\mathrm{LT}=$ live time, $\mathrm{S}=$ sensitivity (defined as CPS/lg), and $\mathrm{cps}=$ counts per second of the standard. Table VIII compares the detection limits between the two techniques which revealed that in both cases the detection limits are almost comparable.
TABLE VII

Comparison of Results of ICP-AES and INAA

\begin{tabular}{ccccc}
\hline Elements & \multicolumn{2}{c}{$\begin{array}{c}\text { Carbon Steel-1 } \\
(\mu \mathrm{g} / \mathrm{mg})\end{array}$} & \multicolumn{2}{c}{$\begin{array}{c}\text { Carbon Steel }-2 \\
(\mu \mathrm{g} / \mathrm{mg})\end{array}$} \\
\hline & ICP-AES & INAA & ICP-AES & INAA \\
\hline $\mathrm{Cr}$ & 3.4 & 3.2 & 0.16 & 0.08 \\
$\mathrm{Zn}$ & 0.15 & 0.11 & 0.14 & 0.12 \\
$\mathrm{Co}$ & 1.25 & 1.30 & 1.31 & 1.32 \\
$\mathrm{Cd}$ & $\mathrm{BDL}$ & $\mathrm{BDL}$ & $\mathrm{BDL}$ & $\mathrm{BDL}$ \\
$\mathrm{Cu}$ & 1.6 & 1.7 & 0.33 & 0.2 \\
$\mathrm{Ca}$ & $\mathrm{BDL}$ & $\mathrm{BDL}$ & $\mathrm{BDL}$ & $\mathrm{BDL}$ \\
$\mathrm{Na}$ & 0.4 & 0.32 & 0.23 & 0.12 \\
$\mathrm{Ni}$ & 3.7 & 3.9 & 0.54 & 0.55 \\
$\mathrm{Mn}$ & 7.4 & 7.5 & 6.2 & 6.0 \\
$\mathrm{Mo}$ & 4.59 & 4.63 & 0.67 & 0.66 \\
$\mathrm{Mg}$ & $\mathrm{BDL}$ & $\mathrm{BDL}$ & $\mathrm{BDL}$ & $\mathrm{BDL}$ \\
\hline
\end{tabular}

$\mathrm{BDL}=$ Below detection limit.

TABLE VIII

Comparison of Detection Limits

Between ICP-AES and INAA

\begin{tabular}{ccc}
\hline Element & \multicolumn{2}{c}{ Detection Limits $(\mu \mathrm{g} / \mathrm{mg})$} \\
\hline & INAA & ICP-AES \\
\hline $\mathrm{Cr}$ & 0.02 & 0.02 \\
$\mathrm{Zn}$ & 0.01 & 0.02 \\
$\mathrm{Ni}$ & 0.01 & 0.02 \\
$\mathrm{Co}$ & 0.02 & 0.02 \\
$\mathrm{Mg}$ & 0.02 & 0.03 \\
$\mathrm{Cu}$ & 0.02 & 0.01 \\
$\mathrm{Ca}$ & 0.04 & 0.03 \\
$\mathrm{Na}$ & 0.02 & 0.06 \\
$\mathrm{Cd}$ & 0.04 & 0.03 \\
$\mathrm{Mn}$ & 0.01 & 0.01 \\
$\mathrm{Mo}$ & 0.03 & 0.04 \\
\hline
\end{tabular}




\section{CONCLUSION}

A systematic study on the spectral interference of emission-rich iron in trace level analytes was carried out using inductively coupled plasma atomic emission spectrometry (ICP-AES) without requiring chemical separation of Fe. It was found that there is no significant contribution of iron due to spectral interference on the analytical wavelengths for $\mathrm{Pb}, \mathrm{Cd}, \mathrm{Mn}, \mathrm{Mo}, \mathrm{Mg}$, Si, $\mathrm{V}, \mathrm{Cu}, \mathrm{Ag}, \mathrm{Ca}, \mathrm{Na}$, and Li. However, the elements $\mathrm{Cr}, \mathrm{Zn}, \mathrm{Ni}, \mathrm{Co}, \mathrm{B}$, and Al were affected in the presence of iron. The contribution to analyte concentration due to spectral interferences was found to vary linearly with the Fe concentration. The concentration of iron was determined and the correction factor for each interfered analytical line was calculated.

Based on the spectral interference study, a rapid, simple and suitable methodology was developed for the determination of trace metallic constituents in carbon steel. Since no chemical separation procedure is involved, the probability of process contamination is minimized. Two carbon steel samples were analyzed for the elements of interest using their respective analytical lines and applying the appropriate correction factors. The results of this study show that $\mathrm{Cr}$, $\mathrm{Zn}, \mathrm{Pb}, \mathrm{Co}, \mathrm{Ni}, \mathrm{B}, \mathrm{Mn}, \mathrm{Mo}, \mathrm{Si}, \mathrm{Al}, \mathrm{V}$, $\mathrm{Na}$, and $\mathrm{Cu}$ were present in both the samples, while $\mathrm{Ca}, \mathrm{Mg}$, and $\mathrm{Cd}$ were found to be below the limits of detection. For comparison, the ICP-AES analytical data were validated using instrumental neutron activation analysis (INAA), and the results were found to be in good agreement.

Received April 8, 2011.

\section{REFERENCES}

1. Metals Handbook, Desk Edition, 2nd edition, ASM International (1998).

2. J. H. Zaidi, S. Waheed, and S Ahmead, Radiochim. Acta 88, 233 (2000).

3. C. Wispelaere, J.P.O.P. de Beeck, and J. Host, Anal. Chim. Acta 70, 1 (1974).

4. D. Sommer and K. Fresenius Ohls, J. Anal. Chem. 298, 123 (1979).

5. J. B. Headridge, Spectrochim. Acta 35B, 785 (1980).

6. B. Lundberg and W. Frech, Anal. Chim. Acta 104, 67 (1979).

7. J. Chen, H. Berndt, G. Tolg, and J. Fresenius, J. Anal. Chem.], 344 , 526 (1992).

8. C. C. Butler, R. N. Kniseley, and V. A. Fassel, Anal. Chem. 47, 825 (1975).

9. A. G. Coedo, T. D. Lopez, and F. Alguacil, Anal. Chim. Acta 315, 331 (1995).

10. M. Gopalkrishnan, K. Radhakrishnan, P.S. Dhami, V.T. Kulkarni, M.V. Joshi, A.B. Patwardhan, A. Ramanujam, and J.N. Mathur, Talanta 44 (2), 169 (1997).

11. K. Satyanarayana and S. Durani, J. Radioanal. and Nucl. Chem. 285 (3), 659 (2010)

12. P.L. Mahanta, G. Chakrapani, and R. Radhamani, At. Spectrosc. 31(1), (2010)

13. S. Chandramouleeswaran and J.C. Upadya, Expl. and Res. for At. Minerals 19, 54 (2009).

14. B. Rajeswari, B.A. Dhawale, T.R.. Bangia, J.N. Mathur, and A.G. Page, $\mathrm{J}$. of Radioanal. and Nucl. Chem. 254 (3), 479 (2002).

15. A.A. Argekar, M.J. Kulkarni, J.N. Mathur, and A.G. Page, Talanta 56 (4), 591 (2002)

16. S. Marin, S. Cornejo, C. Jara, and N. Duran, Fresenius' J. of Anal Chem. 355 (5-6), 680 (1996).

17. P.W.J.M. Boumans, Inductively Coupled Plasma Emission Spectroscopy, Part - 1: Methodology, Instrumentation and Performance, 1st ed. New York (1987).
18. A. Montaser and D. W. Golightly, Inductively Coupled Plasma in Analytical Atomic Spectrometry, VHC Publishers (1990).

19. M. Ochsenkuhn-Petropulu and P. Schramel, Mikrochim. Acta 119, 265 (1995).

20. Y. Fresenius Danzaki, J. Anal. Chem. 356, 143 (1996).

21. M.C. Williams, E.J. Cokal, and T. Niemczyk, Anal. Chem. 58, 1541 (1986)

22. Maria das Gracas, A. Korn, Helena V. Jaeger, Adriana C. Ferreira, and A.C. Inola Costa, Spectrosc. Lett. 33 (2), 127 (2000).

23. Xu Li-Qiang and Rao Zhu, Fresenius Z. Anal. Chem. 325, 534 (1986).

24. M.Vammond and R. M. Alonso, J. Anal. At. Spectrom. 3, 1101 (1988). 